\title{
Ritornelos para o pesquisar no contexto das tecnologias virtuais do sensivel
}

\section{Small returns for research in the context of the virtual technologies of the sensitive}

\begin{abstract}
Resumo: O presente artigo problematiza as tecnologias virtuais e sua concretude imaterial em relação à produção de subjetividade e à produção da pesquisa. O conceito de máquina abstrata de Deleuze e Guattari atravessa a reflexão proposta de modo a oferecer subsídios para pensarmos a rede de tecnologias como produtora de sensibilidades. Tais tecnologias do sensível produzem maquinicamente nossos territórios existenciais e nossos mundos. Pela técnica produzimos a produção de nosso mundo. Esta perspectiva muda o status das discussões metodológicas: de simples técnica utilitarista aquém do sujeito, para tecnologia epistêmicontológica construtora de territórios existenciais. A metodologia constitui-se, assim, como a tecnociência sensível de uma epistemologia específica. Trata-se do forjar de modos de olhar que se coadunem a uma determinada concepção ontológica e criacionista de mundo. Propomos, pois através de oito ritornelos que são compreendidos, como enunciados que podem ser convenientes aos pesquisadores-cartógrafos.

Palavras-Chave: Tecnologia. Pesquisa. Ritornelos.
\end{abstract}

Abstract: this paper brings into matter the virtual technologies and its immaterial tangibility towards the production of subjectivity and the production of research. Deleuze and Guattari's concept of the abstract machine comes between the proposed reflection to offer some aid so that we can think about the net of technologies as a provider of sensitiveness. Such technologies of the sensitive produce our existing boundaries and worlds in a machine-like manner. Through the technique we produce the production of our world. This perspective changes the status of the methodological discussions: from a simple useful technique beyond the subject to a "epistemicontological" technique constructor of existing boundaries. The technology is made therefore like technoscience sensitive to a specific epistemology. It is about the faking of ways of seeing in which they link themselves to a specific ontological and creating conception of the world. Hence, we propose through the eight small returns that are made understood as announcements that can be convenient to the cartographer researchers.

Key-words: Technologies. Research. Small Returns.

FONSECA, Tania Mara Galli; COSTA, Luiz Artur; KIRST, Patrícia Gomes. Ritornelos para o pesquisar no contexto das tecnologias virtuais do sensíveli. Informática na educação: teoria \& prática. Porto Alegre, v.11, n.1, p. 38-46, jan./ jun. 2008.

\author{
Tania Mara Galli Fonseca \\ Universidade Federal do Rio Grande do Sul, Porto Alegre, Brasil \\ Luiz Artur Costa \\ Universidade Federal do Rio Grande do Sul, Porto Alegre, Brasil \\ Patrícia Gomes Kirst \\ Universidade Federal do Rio Grande do Sul, Porto Alegre, Brasil \\ Universidade Luterana do Brasil, Canoas, Brasil
}

\section{As tecnologias virtuais do sensível}

$\mathbf{E}$ m uma época de produções tão sutis como a nossa, a ponto de ser denominada por termos algo intangíveis como capitalismo cognitivo (MARAZZI, 2002), capital imaterial (GORZ, 2005), trabalho imaterial (HARDT; NEGRI, 2004), entre outros, percebemos às claras, a concretude do sutil, as forças produtoras imateriais onde se forjam mundos para além do exclusivamente mineral e orgânico. Assim, a noção de produção ultrapassa a de materialidade, sutilizando-se e percebendo a concretude imaterial da subjetivação e seus modos. Encontramo-nos com estas forças produtoras vivendo em um cotidiano tomado pela imaterialidade das novas mídias e do trabalho criativo, intelectual: forjamos um corpo para o incorpóreo, tornando-o sensível. E convivendo com os modos destes novos corpos os percebemos como um novo conjunto de máquinas com suas tecnologias específicas.

As práticas humanas e inumanas imbricamse adquirindo consistências diversas em suas ressonâncias que as perpetuam. Formam modos de se efetuarem constituindo máquinas geradoras de mundos. Toda uma tecnosfera, 
coadunada à noosfera e ecosfera, nos envolve em artifícios os quais nos possibilitam viver do modo que vivemos. São máquinas abstratas (DELEUZE; GUATTARI, 1976) coadunadas às materiais criando uma dança tecnológica produtora de sensíveis inteligíveis e de inteligíveis sensíveis. Tais tecnologias problemáticas do sensível produzem maquinicamente nossos territórios existenciais, nossos ritornelos que cortam o caosmos e forjam composições mundanas (DELEUZE; GUATTARI, 1997). Processo de forja baseado na técnica do metal, onde o aço atual é amolecido no encontro com a chama alimentada pela atmosfera virtual.

Seguindo este fluxo de invenções, aprendemos com o filósofo das máquinas Gilbert Simondon (2003) a arte do conceito de individuação o qual não apenas ultrapassa e antecede o de indivíduo, como também estende sua abrangência para além do estritamente biológico, revelando a estreita implicação entre a individuação dos seres, dos saberes e dos objetos técnicos. Deste modo, vemos a usinagem de conhecimento entendida segundo os fortes matizes da ontologia: a criação de conhecimento é a criação de existências. O saber não é então uma entidade abstrata que paira plácida sobre o baile das coisas lascivas em seus devires. Antes está encharcado de concretude, produzindo rebentos bastardos da razão, aquém da paternidade da pura representação. O saber se individua constantemente, mutando cores, odores e sabores, alternando suas movimentações e o ritmo da respiração que o faz vibrar. Todo um mundo se individua junto à individuação do espanto sem fôlego em uma boca entreaberta defrontando-se com o intempestivo, ou junto de um estranhamento sem franzir de cenho que não mede outrem pelo mesmo de si.

Desta fusão entre epistemologia e ontologia, obtemos um perspectivismo forte, onde não falamos mais de pontos de vista parciais centrados sobre um mesmo objeto externo e total, mas sim de modos de subjetivação, não havendo externalidade ou totalidade no encontro: antes de formas de ver, são modos de viver. A perspectiva afirma mundos, criando-os e produzindo-os ao afirmar a si mesma. O saber não está imaculado da carne e do desejo, tampouco das relações orgiásticas que o constituem de modo báquico. E, é ao problematizar os ardis desta concepção desnaturando-os, que concebemos as tecnologias virtuais do sensível.

O olhar, assim como o saber, não se dá de forma natural, direta e espontânea. O olhar é constrangido à sua mirada por seus artifícios de tornar visível o sensível: "[...] o olho é uma luz implicada; o olho é a expressão de uma luz possível e a orelha é a expressão de um som possível" (DELEUZE, 1988, p. 413). O sensível erige-se então em uma batalha de possibilidades, desejos, virtualidades e contingências, os quais imbricam um modo de ver singular. Entretanto, não se conclui da artificialidade do sentir, de sua existência em artifícios singulares, que este seja falso ou que deva ser treinado a um correto olhar, livre de sombras e ilusões. Tal olhar transparente de perspectiva é impossível, posto que o ato sensível é demasiado forçado para tal ausência de interesses. Antes, é sempre através de uma série de artifícios que tornamos possível o sentir, é através destes mecanismos da sensibilidade que expressamos um mundo possível, produzido por nossas tecnologias sensíveis. "Sabem, a técnica não é uma invenção dos homens. Talvez o contrário" (LYOTARD, 1997, p. 20). É forçosamente que construímos nossas relações sensíveis as quais nos permitem ser.

Podemos, então, agora, falar de tecnologias virtuais do sensível enquanto o conjunto de práticas problemáticas coadunadas por tensões variantes que possibilitam ao nosso corpo experimentar (produzirexperienciar) um modo de simundo. As técnicas desta tecnologia nos permitem problematizar o sensível efetuando experimentações sensíveis, sendo estas compreendidas a um só tempo como experimentações de experiências (epistemológica) e de práticas de experimentação (ontológica). Experimentação acima de tudo em sua acepção de técnicas de invenção.

A palavra tekhnê referia-se, na Grécia antiga, não simplesmente às condutas para com o arado, ou ao trato com o gado e às maneiras de vencer uma batalha; antes, denotava qualquer forma de produção, artística, "técnica", etc. (MACHADO, 2001). A "gestão-produção das coisas" tomada de forma ampla e quase irrestrita nos leva a repensar o que constitui a concretude de uma produção e, por conseguinte, a efetuação de uma tecnologia ou técnica. Podemos, então, "reencantar o concreto" (VARELA, 2003) problematizando-o e tornando-o muito mais do que material: prenhe de virtualidades. 
Pensamos, aqui, com as tecnologias virtuais do sensível, a técnica como modo de produção de mundos pelo olhar epistêmicometodológico: a construção de uma caixa de ferramentas que produz a produção do nosso mundo. Esta perspectiva muda o status da discussão metodológica: de simples técnica utilitarista aquém do sujeito, para tecnologia epistêmicontológica construtora de territórios existenciais. A metodologia constitui-se, assim, como a tecnociência sensível de uma epistemologia específica. Trata-se do forjar de modos de olhar que se coadunem a uma determinada concepção ontológica de mundo. Uma produção de tecnologias que possibilitem imbricar bons encontros na intricada malha que nos produz.

Com as tecnologias virtuais do sensível modulamos algo da vibração maquínica da nossa pele de modo que esta produza tendências a uma determinada modalidade de encontros sensíveis. Esta superfície profunda se sensibiliza a partir de determinados artifícios, ainda que intempestivos. Tais tecnologias problematizam, aqui, como abrir no corpo os poros disformes que permitirão respirar ares menos simétricos, mas não menos concretos, fazendo-se corpo-de-passagem (SANT'ANNA, 2001) do mundo em sua subjetividade concreta de matéria, ações e afectos. É um duro e árduo trabalho este de fluir o corpo para abarcar as arestas singulares dos processos. E, é com este objetivo que se tecem as tecnologias virtuais do sensível nos ritornelos para o pesquisar.

\section{Ritornelos para o pesquisar}

Se fosse o caso de nossa posição vir a ser reconhecida através de alguma marca, não temos dúvida de que essa poderia ser a da inconformidade com os tradicionais modos de produção do conhecimento, cuja inoperância se efetua naquilo que consideramos de mais significativo no plano de nosso compromisso: a expansão da vida e o aumento de sua potência de diferir. "Nosso pessimismo decorre do tratamento pragmático que quase sempre é utilizado para constituir os saberes, e conseqüentemente, calçar as intervenções realizadas no plano das ciências humanas" (REGIS, 2004 , p. 39). Neste referido modo, platônico e racionalista - , somos levados a reconhe- cer a tendência em buscarmos "encaixar", em modelos pré-estabelecidos e transcendentes, a variedade dos acontecimentos da realidade, negando-lhes a inscrição no tempo bem como as virtualidades que Ihes são imanentes. A aplicação de um 'programa metodológico' a um campo empírico, pode nos levar a concluir, portanto, que estaremos, no próprio ato de pesquisar, relançando supostamente o desconhecido pesquisado, no plano daquilo que já conhecemos, tornando-o, assim, 'familiar' e docilizado. Percebemos que a tendência que inspira análises desta natureza é, em geral, de cunho representacional, ou seja, se insere num vetor de pesquisa que busca, no campo da pesquisa, as representações fantasmáticas de imagens primeiras e ideais. Conhecer, aqui, torna-se sinônimo de reconhecer, e, ciência passa a ser nomeada como busca da verdade.

Se, contudo, ao invés de um programa, viermos a adotar estratégias, tanto para o nosso pensamento quanto para a nossa ação, podemos assegurar, ao menos em tese, nos encontrarmos melhor capacitados para lidar com a dinamicidade e incertezas implícitas ao processo de pesquisa e de produção de mundos.

Em trabalhos anteriores (FONSECA; KIRST, 2003, 2004), exploramos o fazer cartográfico como concernente ao conjunto de estratégias de produção de conhecimento e, por isso mesmo, dotado de potencialidade crítica e clínica. Naquele momento, dizíamos que

[...] o ato de cartografar pode promover, em um só movimento, invenção tanto de um mundo quanto de um sujeito, uma vez que ao colocar em análise as formas que habitam o contemporâneo, seus limites e fronteiras, rebate-as em si mesmas, atiçando-as para provocar o seu plano de alteridade e criação. Tal tarefa incidiria, desta forma, nos próprios modos de produzir o controle da vida, forçando-nos a argüir sobre o que temos sido e sobre as condições que se colocam como fundações de nosso existir (FONSECA; KIRST, 2004, p. 29)

A cartografia, neste sentido, implicaria em rebatermos a forma sobre si mesma, sondá-la enquanto morada do ser, na busca de ampliar sua superfície de contato com o Fora, multiplicar seus planos, agir nos seus limites, não para o seu fundo, mas para todos os seus lados, atuando em sua própria abertura e expansão para o acolhimento de outros vetores 
de existencilialização. Resultaria em uma operação de dobrar-se sobre o que está posto, para fazê-lo desviar-se de si, operação de fora-inclusão da diferença na superfície, provocação de desvios, perturbações e diferenciação na imagem-mundo estabelecida.

Torna-se claro que estamos nos referindo a uma produção complexa, na qual sempre estamos inelutavelmente implicados. Não se trata de conceber em separado os dois termos aqui aludidos: sujeito e objeto, como se cada um vivesse encapsulado em esfera própria, apenas suscetível de vir a ser explicado desde princípios que lhe são exteriores e transcendentes. Acreditamos que Simondon, ao propor o conceito de transdução, nos possibilita cercar de mais perto esta operação que, no processo de cognição, une e embaralha sujeito e mundo. Para o autor (2003, p. 112), a transdução refere-se a

[...] uma operação física, biológica, mental, social, porque uma atividade se propaga gradativamente no interior de um domínio, fundando esta propagação sobre uma estruturação de um domínio operada de região em região: cada região de estrutura constituída serve de princípio de constituição à região seguinte, de modo que uma modificação se estende progressivamente ao mesmo tempo que esta operação estruturante.

Estabelecemos assim, que para o cartógrafo, as relações pensamento/mundo não repousam em uma unidade de identidade, que é a do estado estável em que nenhuma transformação é possível. Ao contrário, na produção de conhecimento, consideramos sujeito e mundo como corpos entrelaçados e contagiados cujos encontros acontecem no registro de uma unidade transdutora, podendo defasarem-se em relação a si próprios, se ultrapassarem, pois o devir lhes é imanente, não se colocando como mera dimensão que Ihes é acrescida. O método, a estratégia, portanto, neste caso, consistiria, nas palavras de Simondon (2003, p. 111):

[...] em não tentar compor a essência de uma realidade por meio de uma relação conceitual entre dois termos extremos, e em considerar qualquer verdadeira relação como tendo posição de ser. A relação é uma modalidade do ser; é simultânea relativamente aos termos de que assegura a existência. Uma relação deve ser apreendida como relação no ser, relação do ser, maneira de ser e não como simples relação entre dois termos que poderíamos conhecer de modo adequado mediante conceitos, porque teriam uma existência efetivamente separada.

Assim, as clássicas operações de dedução e de indução não podem mais vir a ser empregadas quando abandonamos a substância como modelo do ser e quando, ao contrário, concebemos como possível a relação entre dois termos como não-identidade diante de si próprio. No emprego deste modo, os princípios da identidade e do terceiro excluído passam a ser igualmente considerados estreitos e insuficientes, buscando-se em contrapartida, a constituição de uma 'estrutura reticular amplificante' e uma positivação do negativo, uma vez que a aparição deste último não se coloca como oposição ao que existe, mas corresponde a algo que já habitava o plano, como um extra-ser, tenso e virtual, da forma e da configuração pesquisada. Pela transdução, não buscamos determinar parâmetros para uma ciência da prova. Ela refere-se a um modo de pensar cuja maneira de progredir consiste "[...] em seguir o ser em sua gênese, em efetuar a gênese do pensamento ao mesmo tempo em que ocorre a gênese do objeto" (SIMONDON, 2003 , p. 113). Além de uma maneira de progredir do espírito, a transdução manifesta-se também como intuição, visto que ao contrário da dedução, ela não vai procurar alhures um princípio para resolver o problema de um dado domínio: ela extrai a estrutura resolutiva das próprias tensões deste domínio. A transdução também não é comparável à indução, pois esta conserva os caracteres dos termos de realidade, e apesar de extrair-lhes as estruturas de análise, só mantém e considera o positivo, isto é, o que há de comum a todos os termos, eliminando o que eles possuem de singular. A transdução é, ao contrário,

[...] uma descoberta de dimensões, as dimensões de cada um dos termos que o sistema faz comunicar, de tal maneira que a realidade completa de cada um dos termos do domínio possa vir a ordenar-se sem perda, sem redução [...] opera a inversão do negativo em positivo, aquilo por que os termos são díspares é integrado ao sistema de resolução e devém condição de significação [...] a ordem transdutora conserva todo o concreto (SIMONDON, 2003, p. 114).

Se nossas considerações sinalizam para o pesquisar como o revolvimento e atualização de certas potências imanentes ao plano pesquisado e, da mesma forma, não o consideram independentemente do pensamento que 
o pensa e do olhar que o prescruta, torna-se interessante chamarmos para a nossa conversa o conceito de heterotopia, proposto, em 1967, por Michel Foucault. Mais do que qualquer heterotopia, daremos atenção especial àquela que ele denomina heterotopia do espelho, uma vez que esta, se coloca como uma espécie de contra-imagem, de um contra-lugar refletido por nós mesmos quando pensamos contra o que estamos nos tornando. No espelho, estamos lá, do outro lado da superfície, estamos onde não estamos, num espaço virtual, sendo que somos sombra que se dá visibilidade a si mesma, permitindo-se ver-se, ali, onde está ausente. A imagem do espelho exerce um tipo de contra-ação à posição que ocupamos e a partir deste olhar, dirigido a nós próprios, podemos retornar, empreendendo a viagem que nos permite atravessar o ponto virtual que se encontra do lado de lá.

Neste sentido, consideramos importante ressaltar que o modo de fazermos progredir o pensamento em relação à produção de conhecimento, poderá apontar a nossa própria imagem no espelho, imagem daquilo em que estamos nos tornando e assinalamento do que estamos fazendo por nós.

Este modo de pensar implicará o abrir do corpo, o desaprender códigos, o aguçar sensações, o tornar-se passagem de imagens-mundo inimagináveis. Um modo não centrado, conectivo, expansivo e heterogenético que pode conduzir o cartógrafo a uma viagem a si mesmo, e ao que ele nunca pensou poder vir a ser, uma vez que ele, enquanto corpo pensante, se oferece como ferramenta vibrátil para realizar o mundo em si mesmo. Suporte tradutor de fluxos a-significantes, canal de expressão do impessoal e, ao mesmo tempo, sua manifestação encarnada, vivida e subjetivada, o cartógrafo foge às interpretações e busca experimentar o mundo através de suas afecções, do pathos que Ihe é próprio. Neste caso, toda a objetividade se reveste de subjetividade e já não podemos estabelecer disjunções entre os termos sujeito e objeto. Suprimimos objetos e sujeitos e nos resta o incomensurável domínio entrelaçado da objetivação-subjetivação. Cartografar implica produzir uma diferença de natureza na forma, implica realocar sua operação ou estratégia cognitiva para uma aposição de mobilização, maquinismo que lida com trajetos e devires e não mais com pessoas e objetos.
Da mesma forma, nos remetemos a uma nova maneira de viver as relações entre teoriaprática, em que as pressupomos interligadas e se co-produzindo. Sempre parciais e fragmentárias, as relações teoria-prática já não são concebidas sob a forma de um processo de totalização explicativa. É Deleuze (apud FOUCAULT, 1981, p. 8) quem nos ensina a comparar a teoria como 'uma caixa de ferramentas' que deve funcionar. Para ele, a teoria não se totaliza, mas se multiplica e multiplica e a relação de aplicação teoria-prática nunca é de semelhança. Segundo suas palavras (p. 10):

[...] desde que uma teoria penetra em tal ou qual ponto, choca com a impossibilidade de ter a menor conseqüência prática, sem que se produza uma explosão, com a necessidade de outro ponto [...] é uma ação revolucionária que, desde o fundo de seu caráter parcial, se vê determinada a por em questão a totalidade do poder e de sua hierarquia.

Tal como máquina de guerra, pois sua função é produzir o produzir, a cartografia opera por cortes e fluxos importando o que se faz dela e o que faz em si mesma enquanto passeia os acontecimentos. Ele instiga o cientista a situar-se sempre no entre o já instituído e o a instituir, obrigando-o a embrenhar-se nos interstícios para afirmar devires, explodir axiomas e criar outros relevos na paisagem. Trata-se de uma operação de desertificação da paisagem não para esterizá-la nem para despovoá-la, mas para fazer crescer o deserto onde a produção de conhecimento possa se dar mais livremente, sem fronteiras delimitadas e necessidade de passaportes conceituais. No fazer cartográfico, busca-se colocar as variáveis científicas em estado de variação contínua, percorrer o espaço liso no qual não há reproduções aceitáveis e abrir o corpo para um pensamento que, segundo Deleuze e Guattari (1995, p. 48), refere-se a:

[...] um pensamento-acontecimento, hecceidade, em vez de um pensamento-sujeito, um pensamento-problema no lugar de um pensamentoessência ou teorema, um pensamento que faz apelo a um povo em vez de se tomar por um ministério.

Se até este momento buscamos conferir ao pesquisar um elevado estatuto no plano da produção do humano e do mundo, pensamos que a finalização deste texto possa se dar 
através de algumas pro-posições, cujo caráter sintético, entretanto, não poderia ser confundido com preceitos normativos. De nossa experiência, recortamos algumas noções e idéias que, mesmo enquanto segmentos autonomizados de um discurso maior, insistem em uma reverberação criadora potente para transformar todo o conjunto ao qual virão se acoplar.

Com pro-posições queremos marcar posições no plano da pesquisa e considerar o ato de pesquisar como ato analítico que faz, portanto, como já referido acima, sujeito e mundo conversarem e interagirem não no sentido de um intercâmbio, troca ou imitação, mas no da criação de resoluções/saídas ao nó problemático a ser interrogado e decomposto. Não corresponde a um achar soluções e respostas, mas a um modo de constituir a própria problematização à qual se virá a conceder uma "resolução" parcial, instalando-a numa espécie de estado da coisa. Problematizar, aqui, confunde-se com o próprio pesquisar, com a própria produção de um modo de pensar que explora, mais do explica, que transforma aquilo que problematiza e que eleva o meio à finalidade, sem, contudo ser dirigido por qualquer teleologia. No processo de escavação do plano empírico, não sabemos, ao certo, o que viremos a encontrar e o resultado não corresponde a respostas antecipadas. Nosso corpo-vibrátil, na pesquisa, detecta tendências-vetores e nos conduz a sentir os ventos que sopram na etérea atmosfera que envolve mundo e sujeitos. Se pesquisar carrega sentidos nômades, pensamos que instaurar alguma terra/território para que o pesquisador acomode seus pés não seria de todo inconveniente. Assim, chamamos de ritornelos aos enunciados que seguem e os consideramos como parâmetros de consistência subjetiva que podem ser convenientes ao cartógrafo, diante das vertigens dos fluxos desterritorializantes de próprio desejo e devires. Assim o que nas pesquisas tradicionais poder-se-ia chamar de descrição, narrativa ou discurso, a partir deste ponto-devista será chamado de produção existencial ou cartografia do tempo. Os planos da pesquisa são planos de vida. Aqui, o conceito de ritornelo (ALLIEZ, 2000, p. 497):

[...] um ponto de preensão, território, dobra securitária, com risco de um retorno melancólico ao natal, mas é também uma linha potencial cujos pontos podem se redistribuir: distribuição polifônica, variações de velocidade, de densidade de orquestração [...].

As forças liberadas pelo fazer em pesquisa são, precisamente, as forças do tempo, e o ritornelo é composto pelos gestos, lugares e momentos que cabem dentro de certos caminhos da descoberta. Na pesquisa, o meio para a propagação do "ritornelo" é o recorte e o momento da produção - histórico e existencial, o que vem a desbancar outros modos de apreensão daquele tempo. Seria como lançar fronteiras espaciais e luminosas para uma passagem do tempo ou agenciar certa expressão para um momento. No próprio ato de limitar os fluxos do que percebemos é que a expressão é construída. Assim, o tempo é contido e construído, mas, no processo posterior que envolve o olhar de terceiros, tal tempo é desterritorializado com a sobreposição de outro operador com a sua bagagem de instantes, e com isso surgem efeitos de novas demarcações/organizações nos ritmos de derramamento da ampulheta complexa que está invisível dentro de cada pesquisa.

Pesquisador e objeto armam labirintos do tempo e, a partir de seus tempos arranjam a forma onde os passados e os futuros se encontram sob o signo dos ritornelos tornados vivos em cada marca. O passado e o futuro nos empurram para a produção de sentidos, e naquele pedaço de imagem onde paira o tempo de algo que é significativo para o sujeito, então, a vida aflora. "O pequeno ritornelo... é a verdadeira vida... é o que nos salva da corrida para ao túmulo... é a prova do eterno" (ALLIEZ, 2000, p. 503).

Não existem "ritornelos" feitos ou autônomos, só é possível assumir esta função quando deslocados/desterritorializados de seu espaço sendo sugados por uma memória que é singular e também impessoal, vindo a fazer parte da história de uma vida e da história da produção de conhecimento.

\subsection{Ritornelo 1}

O campo empírico a ser pesquisado não emerge de uma origem, ponto original. Deve ser remetido à gênese complexa de sua procedência e emergência. Assim, acontecimentalizá-lo não se refere a encontrar, como nos alerta Foucault (2003), uma constante históri- 
ca ou um traço antropológico imediato, ou ainda uma evidência que se impõe. Consiste em reencontrar conexões, encontros, apoios, bloqueios, jogos de força, estratégias, etc. que, em dado momento formaram o que, em seguida, funcionará como evidência, universalidade, necessidade. Acontecimentalizar corresponde à desmultiplicação causal que, por sua vez, consiste em analisar o acontecimento segundo os processos múltiplos que o constituem. Constituir um poliedro de inteligibilidade, cujo número de faces não se encontra previamente definido e nunca pode ser legitimamente concluído. Decomposição interna e relações de inteligibilidade caminham juntas.

\subsection{Ritornelo 2}

Os elementos que são postos em relação são polimorfos e não correspondem a uma estrutura fixa e unitária que dá sustentação ao acontecimento. A única estrutura admissível é a da composição incessante de um complexo jogo de forças, sempre em movimento e singularmente associado. O que importa é a contingência que faz com que as coisas venham a ser como são e como nos parecem ser.

\subsection{Ritornelo 3}

Antes de ser escolhido e selecionado, o campo é que elege aquele que vai problematizá-lo, oferecendo-se como um plano de composição para diversas possibilidades. A relação entre campo a ser pesquisado e sujeito pesquisador é de implicação/transdução e não de exterioridade. Os interesses, mesmo os científicos, são fabricados pelas condições do contexto no qual se inscreve o pesquisador, o que permite colocar em análise a questão da autoria individual e espontaneísta em contrapartida daquela considerada sempre parte de um coletivo de enunciação. Os interesses se revelam como efeitos de associações complexas entre as tendências do território existencial do sujeito, abarcando seus desejos e seus valores e as condições de enunciação possíveis do campo social em dado momento histórico. O dizer, o escutar e o ver resultam, portanto, de um regime de luminosidade própria a cada tempo social, o que tem por conseqüência a produção de saberes que são entendidos como efeitos de saber-poder.

\subsection{Ritornelo 4}

Toda a produção de conhecimento é ao mesmo tempo objetivante e subjetivante, uma vez que a mesma não se inscreve a partir de uma busca da verdade, mas na exploração possível do campo problematizado a partir do olhar do pesquisador. O olhar é construído tanto pelas condições singulares do pesquisador para deixar-se tornar corpo-de-passagem para as forças imbricadas no campo pesquisado, quanto pelas ferramentas conceituais de que dispõe para produzir fissuras nos objetos, nas coisas e nas palavras de modo a dar a ver o que nelas se encontra para além dos códigos lingüísticos. Toda a produção de conhecimento implica-se com a invenção de mundos e a do próprio sujeito conhecedor.

\subsection{Ritornelo 5}

O campo de pesquisa é rizomático e o mergulho para abrí-lo e explicitá-lo opera como uma espécie de corte em seus tecidos. O campo apresenta-se como um plano estendido que deve ser distendido pelo olhar que analisa, tal como uma pele que, distendida e estirada, dá a ver o interior de suas dobras. o campo de pesquisa é fabricado pelo olhar do pesquisador, o que inclui os conceitos-ferramentas com que aquele opera. Sempre composto, ele não se coloca como uma objetividade una e totalizada, conjunto fechado e exterior a nós e do qual viremos conhecer a verdade completa por sucessivas e cumulativas aproximações. Procedemos sempre por cortes e guiados pelo princípio do não, pois podemos 'querer navegar para as Índias e descobrir a América'. O corte do olhar sobre o campo opera como subtração antes do que acréscimo, pois considera-se que todo o olhar é limitado e limitante e restringe o campo de possibilidades de leitura e tradução.

\subsection{Ritornelo 6}

O percurso da pesquisa, através dos nossos cruzamentos no campo, produz ziguezagues; andamos sempre obliquamente e não em linhas diretas e estradas retas. Produzimos labirintos nas escavações do terreno, lugares de resistência e perfuração lá onde a matéria se faz plástica e deixa-nos entrar, para subtrair seu sentido e aprisioná-lo em significados. Assemelhamo-nos, neste sentido, às toupeiras que cavam sua morada com seu próprio corpo Quando nosso andar se produz como rasgo e risco, quando desejamos romper as evidências e perfurá-las, o lapso, o ato falho, 
os desvios fazem parte do processo. Nosso método implica em focalizar o fora de foco, o desviado.

\subsection{Ritornelo 7}

O ato analítico é um ato de coragem por nos colocar face a face com o nosso fora, com aquilo que não sabemos, com aquilo que constitui a nossa alteridade. No ato analítico, somos defrontados com a precariedade de nossos saberes e sua fragilidade. Este corresponde ao seu risco.

Na pesquisa, o fazer se implica no feito e, portanto, o método, não se coloca como uma estrada pavimentada que orienta a direção do andar. São os conceitos e sua trama que fornecem ou não, sustentação às andanças do percurso e suas derivas. Não se trata de antecipar o fazer das buscas. Trata-se de ir em busca, tatear, sondar como um agrimensor sonda o solo antes de lançar-lhe as sementes. Talvez ainda possa ser mais instigante essa semeadura do pesquisador: do reviramento do solo, ele Ihe extrai as sementes, tornando visível aquilo que era imanente àquele solo. Ele não produz o visível. Ele torna visível.

Na pesquisa, o fazer deve valorizar o ínfimo, o mínimo, o ordinário, operando-se aí um certo contraponto estilístico em relação a uma certa lógica de produção de conhecimentos que, estando voltada para a fixação de leis gerais e universais, despreza as microevoluções que se dão incessantemente entre os elementos de um campo. Trata-se de con- cretizar um perspectivismo micropolítico e minoritário com a expectativa de dar a ouvir e ver manifestações de proto-mundos em nascimento, ali, ainda rejeitados e balbuciantes, mas potentes para virem a ser agenciados para um existir estruturado.

\subsection{Ritornelo 8}

Dar voz e vez a manifestações que, mesmo frágeis, destoam e reviram aquilo que se pode encobrir sob nome de consenso da normalidade estatística. Este é o aspecto éticoestético do pesquisar. A superação e o ultrapassamento do humano tal como ele se coloca no presente, exercício de uma vontade de potência que antes do que se deter no já feito, demora-se em examinar os modos como os sujeitos resistem ao que lhes é contemporâneo, entendendo-se aqui, que pesquisar pode ser colocado como ato de resistência e combate ao presente, como re-existência, ou seja, reinvenção do próprio viver.

Não recusar os fracassos e os erros da processualidade, pois eles fazem também parte da história das práticas. Trabalhar com a perspectiva de positivar a atividade imaginativa e criadora, mesmo que nem sempre eficaz e exitosa pode nos introduzir no próprio acontecimentalizar, permitindo-nos valorizar as múltiplas manobras e astúcias que são empregadas pelos agentes sociais na invenção do cotidiano de seu tempo. Significa, outrossim, situar as realizações humanas como obras coletivas de um tempo criativo.

\section{Referências}

ALLIEZ, Éric. Gilles Deleuze: uma vida filosófica. São Paulo: Ed. 34, 2000.

DELEUZE, Gilles. Diferença e repetição. Rio de Janeiro: Graal, 1988.

DELEUZE, Gilles; GUATTARI, Felix. O anti-edipo: capitalismo e esquizofrenia. Rio de Janeiro: Imago, 1976.

DELEUZE, Gilles; GUATTARI, Felix. Mil platôs: capitalismo e esquizofrenia. Rio de Janeiro: Ed. 34, 1995. v. 1.

DELEUZE, Gilles; GuATTARI, Felix. O que é a filosofia? São Paulo: Ed. 34, 1997.

FONSECA, Tania Mara Galli; KIRST, Patrícia Gomes. (Orgs.). Cartografias e devires: a construção do presente. Porto Alegre: Ed. UFRGS, 2003.

FONSECA, Tania Mara Galli; KIRST, Patrícia Gomes. O desejo de mundo: um olhar sobre a clínica. Revista Psicologia \& Sociedade, Porto Alegre, v. 16, n. 3, p. 29-34, set./dez. 2004. 
FOUCAULT, Michel. Um diálogo sobre el poder y outras conversaciones. Madrid: Alianza, 1981.

FOUCAULT, Michel. De outros espaços. Tradução: Pedro Moura. Conferência proferida no Cercle d'Études Architecturales, Paris, 14 mars 1967. Disponível em: <http://www.virose.pt>. Acesso em: 2008.

FOUCAULT, Michel. Mesa-Redonda em 20 de maio de 1978. In: FOUCAULT, Michel. Ditos e escritos: estratégia poder-saber. Rio de Janeiro: Forense Universitária, 2003. p. 335-354. v. 4.

GORZ, André. O imaterial: conhecimento, valor e capital. São Paulo: Annablume, 2005.

HARDT, Michael; NEGRI, Antonio. Império. Rio de Janeiro: Record, 2004.

LYOTARD, Jean-François. O inumano. Lisboa: Estampa, 1997.

MACHADO, Arlindo. Máquina e imaginário: o desafio das poéticas tecnológicas. São Paulo: EDUSP, 2001.

MARAZZI, Christian. A crise na new economy e o trabalho das multidões. In: COcCO, Giuseppe; HPSTEIN, Graciela (Orgs.). As multidões e o Império: entre globalização da guerra e universalização dos direitos. Rio de Janeiro: DP\&A, 2002.

REGIS, Vitor Martins. O acontecimento democracia corinthiana: cartografando estratégias de resistência ao modo de subjetivação capitalístico através do plano das práticas esportivas. 2004. 143 f. Dissertação (Mestrado em Psicologia Social e Institucional)- Instituto de Psicologia, Universidade Federal do Rio Grande do Sul, Porto Alegre, 2004.

SANT'ANNA, Denise Bernuzzi de. Corpos de passagem: ensaios sobre a subjetividade contemporânea. São Paulo: Estação Liberdade, 2001.

SIMONDON, Gilbert. A gênese do indivíduo. In: PELBART, Peter Pál; COSTA, Rogério. (Orgs.). Cadernos de subjetividade: o reencantamento do concreto. São Paulo: Hucitec, 2003. p. 98-117.

VARELA, Francisco. O reencantamento do concreto. In: PELBART, Peter Pál; COSTA, Rogério. (Orgs.). Cadernos de subjetividade: o reencantamento do concreto. São Paulo: Hucitec, 2003. p. 71-86.

Recebido em março de 2008

Aceito para publicação em junho de 2008

Tania Mara Galli Fonseca

Professora do Programa de Pós-graduação em Psicologia Social e Institucional e do Programa de Pós-graduação em Informática na Educação (PPGIE) da Universidade Federal do Rio Grande do Sul (UFRGS).

tfonseca@via-rs.net

\section{Luiz Artur Costa}

Psicólogo, Doutorando do PPGIE/UFRGS.

lartur@cpovo.net

\section{Patrícia Gomes Kirst}

Psicóloga, Professora da Universidade Luterana do Brasil (ULBRA). Doutoranda do PPGIE/UFRGS.

pgomes.voy@terra.com.br 